\title{
ATP transporters in the joints
}

\author{
Ane Larrañaga-Vera ${ }^{1} \cdot$ Miguel Marco-Bonilla $^{2} \cdot$ Raquel Largo $^{2} \cdot$ Gabriel Herrero-Beaumont $^{2} \cdot$ Aránzazu Mediero $^{2}$. \\ Bruce Cronstein ${ }^{1}$
}

Received: 12 April 2021 / Accepted: 9 July 2021 / Published online: 15 August 2021

(c) The Author(s) 2021

\begin{abstract}
Extracellular adenosine triphosphate (ATP) plays a central role in a wide variety of joint diseases. ATP is generated intracellularly, and the concentration of the extracellular ATP pool is determined by the regulation of its transport out of the cell. A variety of ATP transporters have been described, with connexins and pannexins the most commonly cited. Both form intercellular channels, known as gap junctions, that facilitate the transport of various small molecules between cells and mediate cell-cell communication. Connexins and pannexins also form pores, or hemichannels, that are permeable to certain molecules, including ATP. All joint tissues express one or more connexins and pannexins, and their expression is altered in some pathological conditions, such as osteoarthritis (OA) and rheumatoid arthritis (RA), indicating that they may be involved in the onset and progression of these pathologies. The aging of the global population, along with increases in the prevalence of obesity and metabolic dysfunction, is associated with a rising frequency of joint diseases along with the increased costs and burden of related illness. The modulation of connexins and pannexins represents an attractive therapeutic target in joint disease, but their complex regulation, their combination of gap-junction-dependent and -independent functions, and their interplay between gap junction and hemichannel formation are not yet fully elucidated. In this review, we try to shed light on the regulation of these proteins and their roles in ATP transport to the extracellular space in the context of joint disease, and specifically OA and RA.
\end{abstract}

Keywords Cx43 $\cdot$ Panx $1 \cdot$ Panx $3 \cdot$ Joint diseases

\section{Joint diseases}

A number of metabolic, immunologic, inflammatory, and degenerative diseases affect the structures of the joint [1]. They result in reduced mobility and can be extremely painful and debilitating as they progress toward mobility failure. These problems are a leading cause of disability worldwide, representing a principal cause of dependence in the elderly, and can lead to increased mortality [2, 3]. Two of the most common disorders of the joint are osteoarthritis (OA) and rheumatoid arthritis (RA) [4, 5]. The socioeconomic burden of these pathologies is enormous; by 2040 , nearly 78 million US adults are expected to have some form of arthritis

Aránzazu Mediero

aranzazu.mediero@quironsalud.es

1 Department of Medicine, Division of Translational Medicine, NYU Langone Health, New York, NY, USA

2 Bone and Joint Research Unit, IIS-Fundación Jiménez Díaz UAM, 28040 Madrid, Spain diagnosed [6]. OA, the most common form of arthritis, affected up to $14 \%$ US adults (32.5 million) in 2008-2014, according to United States Bone and Joint Initiative [7], and was responsible for $2.4 \%$ of all healthcare visits in that period. RA, an autoimmune form of inflammatory arthritis, has an estimated prevalence of $2 \%$ among the US population 60 years of age and older [8]. OA is predominantly a degenerative disease that can affect almost any joint, but generally affects the hands, knees, hips, and feet, aging is its primary risk factor [9]. OA causes cartilage breakdown, subchondral bone sclerosis, osteophyte formation, and synovial inflammation, leading to joint pain and physical disability in the aging population [10]. RA is a chronic autoimmune disease that can affect any joint, but generally involves the large and small joints of the hands, wrists, and feet and tends to be symmetrical in its effects [11]. RA is characterized by pain, swelling, and destruction of bones and cartilage, ultimately leading to joint destruction and disability [12]. It is primarily driven by a significant synovial inflammatory response involving the innate and adaptive immune system [13], in 
which fibroblasts in the synovium transform to an invasive phenotype, and inflammatory cells induce cartilage destruction and osteoclast generation that result in bone erosion, a hallmark of RA [14]. Although the two diseases differ in etiology, both trigger progressive joint destruction characterized by pathological changes in articular cartilage, bone, and synovium [5].

Articular cartilage is responsible for reducing friction and cushioning the impact produced during movement [15]. This avascular, aneural, and alymphatic tissue provides an elastic and resistant structure on the surface of the joints. Cartilage is formed by a single cell type, the chondrocyte, which secretes the matrix [16].

Underlying bone, separated from the cartilage by the cement line, is constituted of a thin cortical lamella and the underlying trabecular cortical bone [17]. Bone is a mineralized connective tissue comprising three main types of cells: osteoblasts, osteocytes, and osteoclasts. Bone exists in a constant state of remodeling, which is important for the maintenance of normal skeletal structure and function. Osteoblasts synthesize the matrix and play a major role in bone mineralization, formation, and deposition; osteoclasts are multinucleated giant cells that originate from the hematopoietic lineage and are responsible for the resorption of the mineralized bone matrix [18]. Osteocytes are derived from osteoblasts, are embedded within the mineralized matrix and are connected to each other by an intricate network of canalicular channels that coordinate the actions of osteoblasts and osteoclasts via the production of signaling molecules and sense mechanical stress [19].

The synovial membrane is the soft tissue lining the cavities of diarthrodial joints. Its main function is to produce the synovial fluid that minimizes joint wear and provides nutrients to the cartilage. In joint disease, the aggressive transformation of synoviocytes produces an inflammatory infiltrate that can destroy articular cartilage and cause bone erosion [14].

As the world population ages, the incidence of joint diseases is projected to rise significantly in future [7]. Therefore, increasing efforts are underway to find new treatments. There has been significant success in treating RA with drug therapy, including the introduction of new biologic and small-molecule drugs. In contrast, no new medical therapies for OA have been developed, although advances in orthopedic surgery can offer symptomatic relief for many patients.

\section{ATP transporters}

Extracellular adenosine triphosphate (ATP), a leading extracellular signaling molecule acting in diverse physiological and pathological processes, has been shown to have a role in joint disease. Adenine nucleotides act as autocrine and paracrine signaling molecules at a large number of purinergic receptors (P2 receptors) that are expressed to varying degrees on different cell types. Extracellular nucleotidases regulate extracellular ATP levels by dephosphorylating ATP to adenosine, which acts as an agonist at $\mathrm{P} 1$ receptors (a second class of purinergic receptors) [20].

As in other systems, released ATP in the bone microenvironment binds to purinergic receptors in an autocrine or paracrine manner. In the immune system, ATP released from damaged cells promotes cell migration through paracrine signaling [21, 22], whereas ATP released from migrating cells enhances cell motility in an autocrine manner [22-24]. This autocrine loop is essential for macrophage chemotaxis [25]. At least nine possible autocrine loops exist in resident peritoneal macrophages, with any one of three redundant feedback loops terminating on P2Y2, P2Y12, or adenosine receptors sufficing for efficient chemotaxis [25, 26]. In the absence of pannexin-1 (Panx1), P2Y2 or P2Y12 mice exhibited efficient chemotactic navigation. This is blocked in the presence of apyrase as it degrades ATP and ADP, and also with the inhibition of multiple purinergic receptors [25]. This chemotactic function of the purinergic loop is activated in conditions such as inflammation, infection or cell necrosis [24]. Another example can be observed in microglia, where cells release ATP as positive feedback to the increased extracellular ATP, via lysosomes. This local signal can be amplified to induce migration of remote microglia, contributing to regenerative ATP signaling in the brain [24]. Chemoattraction also occurs in dendritic cells, where the activation of the $\mathrm{P} 2 \mathrm{X} 7$ receptor by ATP, through Panx 1 induces plasma membrane permeabilization contributing to the release of ATP [27]. This autocrine purinergic receptor signaling is also essential to amplify the action of platelet activators [28, 29].

Several different mechanisms exist to transport ATP out of the cell to the extracellular space, including channeldependent mechanisms such as those involving connexin $(\mathrm{Cx})$ hemichannels and pannexin (Panx) channels [30, 31].

\section{Connexins}

Connexins are composed of four transmembrane domains, two extracellular loops, and intracellular $\mathrm{N}$ - and C-termini. Connexins are a family of proteins that form hemichannels (or connexons) that can in turn form intercellular gap junctions. More than 20 human connexin isoforms with differential functional properties and tissue distribution have been identified. They are commonly denoted by the word connexin, abbreviated $\mathrm{Cx}$, followed by the molecular weight [32]. Connexin hemichannels are formed by the oligomerization of six connexins, which can be six monomers of the same connexin or a combination of different connexins [33]. Two opposing hemichannels on adjacent cells can form a 
gap junction that facilitates heterocellular communication [31].

Gap junctions and their importance in cell-to-cell transport and communication have been extensively studied [34]. The functionality of unopposed hemichannels, although a newer concept, is also well documented. In brief, connexin hemichannels form pores in the cell membrane that allow the transport of small molecules such as ATP, amino acids, reduced glutathione, $\mathrm{NAD}^{+}, \mathrm{IP}_{3}$, prostaglandin $\mathrm{E}_{2}$, and cyclic nucleotides to the extracellular space [35]. They can switch between open or closed conformation, and their pore, which is closed by default, can be induced to open in response to various stimuli, including changes in extracellular calcium concentrations, cytosolic $\mathrm{pH}$, or stress conditions $[33,36]$.

Several connexin isoforms have been reported to be capable of releasing ATP through unopposed hemichannels from different cell types, including Cx26, Cx30, Cx32, $\mathrm{Cx} 36, \mathrm{Cx} 40$, and $\mathrm{Cx} 43$, with $\mathrm{Cx} 43$ being the best studied [30, 37-39].

\section{Pannexins}

Pannexins are the human homologues of innexins, the proteins that constitute invertebrate gap junctions. Three isoforms, Panx1, Panx2, and Panx3, have been identified, although Panx1 is the most ubiquitously expressed and the best studied. Pannexin channels are involved in releasing extracellular ATP as a paracrine signaling ligand associated with inflammatory events [40, 41]. Panx 1 can be activated and release ATP at physiological $\mathrm{Ca}^{2+}$ concentrations and membrane potentials in response to mechanical stimulation, caspase cleavage, or extracellular $\mathrm{K}^{+}$[42-45].

Pannexins exist in the membrane as tetraspan proteins with intracellular $\mathrm{N}$ - and $\mathrm{C}$-termini. Panx 1 can be found as a hexamer and was recently described as an heptamer [46-48], while Panx3 forms hexameric single-membrane channels, and Panx 2 is predicted to exist as heptamers and octomers. Pannexins can function as single-membrane channels and do not form gap junction channels $[49,50]$.

Shestopalov and Panchin have reported that Panx 1 is expressed broadly, whereas Panx 2 is expressed mainly in brain, and Panx3 in skin and connective tissues [51]. Northern blot studies indicate that Panx 1 is ubiquitously expressed in human tissues, including the brain, lung, liver, skin, heart, skeletal muscle, spleen, thymus, pancreas, and colon [52]. Using custom-designed anti-Panx 1 antibodies, Panx 1 expression has been found in the human brain, with variable levels in the lung, spleen, kidney, heart ventricle, and skin and in murine ear and tail cartilage [53]. Based on expressed sequence tags, mammalian Panx3 has been identified in synovial fibroblasts, osteoblasts, joints in murine paws, inner ear cartilage, and cochlear bone [52, 54]. Moreover, Panx 3 has been detected by in situ hybridization in pre-hypertrophic chondrocytes, perichondrium and osteoblasts of embryonic day (E) 16.5 mice [55]. All three pannexin subtypes have been identified in several cultured mouse cell lines, including osteoblast (MC3T3-E1), chondrocyte (ATDC5), and osteoprogenitor cell lines ( $\mathrm{C} 2 \mathrm{C} 12)$, as well as in primary osteoblasts [56] (Table 1).

Panx 1 can be inactivated by ATP release, $\mathrm{CO}_{2}$-mediated cytoplasmic acidification, channel blockers, or mimetic peptides $[57,58]$. Another regulatory mechanism that has been proposed is phosphorylation of Panx1. During acute vascular inflammation, Panx 1 phosphorylation at tyrosine 198 by Src-family tyrosine kinases results in increased channel activity [59]. Sustained neuronal depolarization is mediated by Panx1 activation thought phosphorylation of tyrosine 308, allowing the activation of NMDA receptors during anoxia [60]. Panx 1 phosphorylation can also mediate decreases in channel activity, as observed in HEK-293 human embryonic kidney cells in which Panx1 channels were inhibited by nitric oxide [61].

Although there is considerable information available on the actions of connexins and pannexins in cellular ATP release, determining their relative contributions to ATP release and other signaling events is a major challenge in the field $[40,41]$. In this review, we focus on the expression and activity of these channels in joint diseases.

\section{ATP transporters in joint diseases}

\section{Cx43 in the joint}

Although diverse connexins have been identified in joint tissues, $\mathrm{Cx} 43$ is the most widely expressed, found in chondrocytes, synovial fibroblasts, and bone cells, and it is considered to play a role in a variety of musculoskeletal pathologies including OA, RA, and osteoporosis.

One of the most important hallmarks of OA and RA is the destruction of cartilage, and $\mathrm{Cx} 43$ is broadly expressed in chondrocytes, which produce and maintain cartilage. Because these cells are commonly found in individual lacunae, Cx43 is more likely to be forming hemichannels that do not constitute gap junctions; indeed, the presence of hemichannels in chondrocytes has been confirmed in vitro (Fig. 1) [62]. However, the specific role of connexins in particular pathologies remain to be fully elucidated.

Chondrocytes from patients with OA are reported to express more $\mathrm{Cx} 43$ than healthy chondrocytes [63]. This phenomenon might be a consequence of the activation of a repair response, also observed in wound healing, that may maintain chondrocytes in a more immature, proliferative state. Although increased Cx43 expression enables constant ECM remodeling, in the long term increased Cx43 
Table 1 Roles of connexin and pannexin channels in cartilage and bone cell lines

\begin{tabular}{|c|c|c|}
\hline Channel & Cell type & Function \\
\hline \multirow[t]{5}{*}{$\mathrm{Cx} 43$} & Chondrocytes & $\begin{array}{l}\text { - OA chondrocytes have increased Cx43 expression compared to healthy chondrocytes [63] } \\
\text { - The inflammatory environment in rheumatic joints enhances Cx43 function in cartilage [38] }\end{array}$ \\
\hline & Synoviocytes & $\begin{array}{l}\text { - OA synoviocytes have increased Cx43 expression compared to healthy synoviocytes [63] } \\
\text { - Cx43 induces the expression of OA-associated genes such as MMP genes or ADAMTS [81] }\end{array}$ \\
\hline & Osteoblast & $\begin{array}{l}\text { - Cx43 inhibits osteoblast precursor proliferation }[89,90] \\
\text { - Cx43 is necessary for the anabolic proprieties of PTH [92-94] } \\
\text { - Diminished Cx43 levels influence the activity of bisphosphonates, reducing their anti-apoptotic effects on } \\
\text { osteoblasts [95] }\end{array}$ \\
\hline & Osteocytes & $\begin{array}{l}\text { - Cx43 hemichannels are essential for osteocyte viability [86] } \\
\text { - Cx43 is responsible for the mechanosensing properties of osteocytes by promoting ATP release [97] }\end{array}$ \\
\hline & Osteoclasts & - $\mathrm{Cx} 43$ is central to cell fusion in osteoclastogenesis in vitro [101] \\
\hline \multirow[t]{4}{*}{ Panx1 } & Chondrocytes & - Panx1 mediates cell-to-cell interaction in response to cell stiffness [63] \\
\hline & Osteocytes & $\begin{array}{l}\text { - Panx1 forms a complex with the P2X7 receptor that promotes NLRP3 inflammasome activation [110] } \\
\text { - Panx1 enhances RANKL expression under apoptotic conditions [112] } \\
\text { - Panx1 enhances bone resorption in response to apoptosis [116] }\end{array}$ \\
\hline & Osteoclast & - Panx1 is essential for osteoclast differentiation [114] \\
\hline & Osteoblast & - Panx1 increases RANKL expression [112] \\
\hline Panx2 & Osteoblast & - Panx2 expression levels do not change during osteoblast differentiation [132] \\
\hline \multirow[t]{2}{*}{ Panx3 } & Chondrocytes & $\begin{array}{l}\text { - Panx3 promotes chondrocyte differentiation by regulating intracellular ATP/cAMP levels [55] } \\
\text { - Panx3 inhibits cell proliferation [55] } \\
\text { - Panx3 induces ATP release during joint damage and triggers cartilage and joint destruction in OA } \\
\text { [136-138] }\end{array}$ \\
\hline & Osteoblast & $\begin{array}{l}\text { - Panx3 promotes osteoblast differentiation [134] } \\
\text { - Panx3 is not required for postnatal bone remodeling [132] }\end{array}$ \\
\hline
\end{tabular}

expression and function could lead to the gradual formation of poor-quality fibrocartilage (Fig. 1) [64].

Connexin hemichannels are reported to respond to cyclical mechanical loading in cartilage by increasing the concentration of ATP in the extracellular space, which would activate $\mathrm{P} 2$ receptors, calcium signaling cascades and, after ATP is dephosphorylated to adenosine, P1 receptors. This increase in ATP release is significantly reduced in the presence of flufenamic acid, an hemichannel inhibitor [65].

Cx43 hemichannels function as mechanosensitive ATP-release channels in different cell types [66-68]. Both bovine and human explant chondrocytes express $\mathrm{Cx} 43$ in the superficial region, down to approximately $200 \mu \mathrm{m}$ below the articular surface [62]. This suggests that $\mathrm{Cx} 43$ performs uncoupled mechanotransduction primarily in the superficial/ middle zone of articular cartilage through mechanotransduction pathways different from those operating in the cells in deeper zones. Moreover, this could be related to the way that (as shown in other cell types) hypoxia regulates $\mathrm{Cx} 43$ dephosphorylation, translocation, and proteosomal degradation [69]. Suggestively, the size of this subpopulation of mechanosensitive chondrocytes expressing Cx43 in the cilium $(\sim 15 \%)$ is very similar to that of the subpopulation showing mechanosensitive purinergic $\mathrm{Ca}^{2+}$ signaling [70]. ATP may activate $\mathrm{P} 2$ receptors and thereby activate intracellular $\mathrm{Ca}^{2+}$ signaling cascades that have an anabolic effect, upregulating proteoglycan and collagen synthesis and cell proliferation [71, 72]. In contrast, chondrocytes isolated from OA cartilage do not show mechanically induced ATPmediated hyperpolarization, even though P2Y2 mRNA expression is similar in normal and OA cells [72]. This indicates that the abnormalities of mechanotransduction in $\mathrm{OA}$ are not related to differences in $\mathrm{P} 2$ receptor expression but rather involve ATP desensitization due to an increased levels of ATP in the synovial fluid in OA [72, 73]. Moreover, Cx43 has been detected in meniscal cell clusters, suggesting that it may be connected to the development of OA [74, 75]. Furthermore, $\mathrm{Cx} 43$ and $\mathrm{Cx} 45$ levels within the damaged superficial zone and middle zone cartilage are elevated in patients with OA [62].

Cx43 might also be acting through channel-independent mechanisms in OA, working as a scaffold protein [76] binding to cytoskeletal proteins and regulating cytoskeletal architecture and cell proliferation [77, 78].

The inflammatory environment in rheumatic joints can further contribute to the regulation of $\mathrm{Cx} 43$ in cartilage. Inflammation, similarly to mechanical load, causes increased production and release of ATP by opening plasma membrane hemichannels; this leads to the activation of purinoceptors, resulting in increased calcium release [79]. Interleukin 1 (IL-1) is the best-studied cytokine associated with rheumatic diseases and is well 


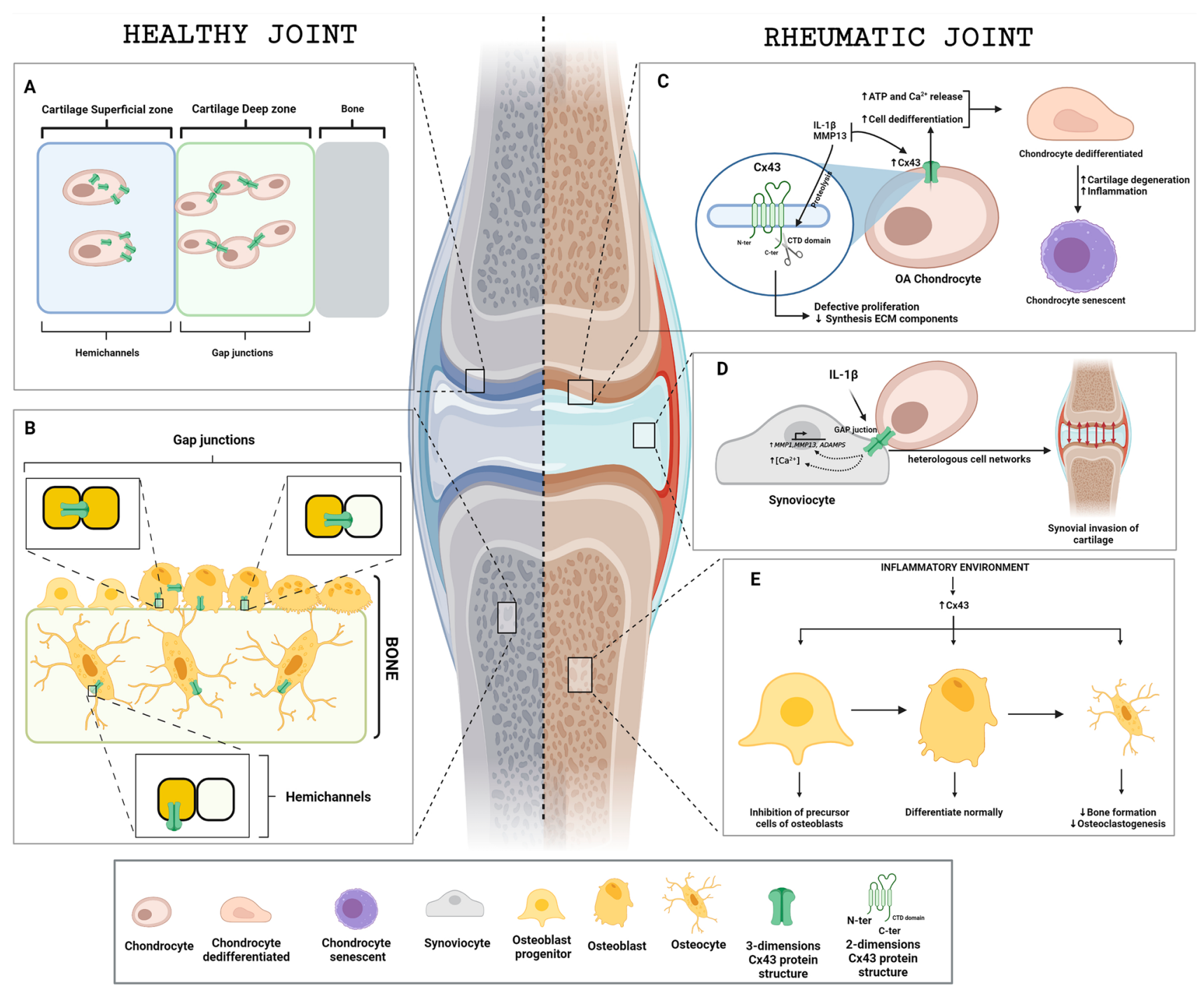

Fig. 1 Role of connexin $43(\mathrm{Cx} 43)$ in healthy and arthritic joints. A) Under homeostatic conditions, the distribution of $\mathrm{Cx} 43$ (green structures) in cartilage depends on the location of chondrocytes in the tissue. In the area near the synovial capsule, $\mathrm{Cx} 43$ has formed hemichannels in chondrocytes. In contrast, the deep zone of the cartilage contains more abundant chondrocytes that allow the formation of gap junctions, favoring cell-to-cell interaction. B) In bone, Cx43 in osteoblasts forms both hemichannels and gap junctions to interact with proximal osteoblasts. In osteocytes, $\mathrm{Cx} 43$ alone maintains the formation of hemichannels. C) The inflammatory environment of an arthritic joint favors the expression of MMP13 and IL-1 $\beta$. This increase is related to a rise in $\mathrm{Cx} 43$ in chondrocytes, which leads in to

established to promote cartilage destruction. In rabbit articular chondrocytes, IL-1 increases cytosolic $\mathrm{Ca}^{2+}$ concentrations, resulting in overexpression of $\mathrm{Cx} 43$. Tonon et al. have suggested that IL-1 could increase the abundance of gap junctions between chondrocytes and synoviocytes, forming heterologous cell networks and favoring synovial invasion of the cartilage (Fig. 1) [80]. However, these experiments were performed under mechanical the release of calcium and ATP and to a dedifferentiation process that promotes chondrocyte senescence due to progressive degradation of the cartilage. D) The increase in $\mathrm{Cx} 43$ due to increased IL- $1 \beta$ allows the overexpression of genes associated with $\mathrm{OA}$, such as $M M P 1$, $M M P 13$, and $A D A M P S$, and the release of intracellular calcium. It also promotes interaction with proximal chondrocytes through the formation of gap junctions, which leads to the proliferation of synoviocytes in the cartilage. E) In bone, inflammatory conditions together with higher $\mathrm{Cx} 43$ abundance lead to the inhibition of osteoblast precursors and a decrease in bone formation and osteoclastogenesis in osteocytes in vitro

stimulation, and the potential role of hemichannels cannot be fully established without further studies.

Another proposed role of $\mathrm{Cx} 43$ on chondrocytes relates to the hemichannel C-terminal domain (CTD). Recent studies reveal that CTD deficiency in mice alters chondrocyte structure and phenotype, leading to defective cellular proliferation and decreased synthesis of matrix components. $\mathrm{Cx} 43$ is a substrate for a variety of metalloproteases (MMP) 
that are upregulated in the joints of individuals with OA as a consequence of inflammation. MMP proteolysis of CTD may contribute to the phenotypic changes associated with functional alterations of $\mathrm{Cx} 43$ that lead to defective tissue repair and disease progression, especially considering that CTD is a pivotal player in regulating the chemical gating of Cx43 channels that influence the release of ATP [78].

Similar to cartilage, OA synovial membrane also shows increased $\mathrm{Cx} 43$ expression as compared to healthy tissue. In synoviocytes, $\mathrm{Cx} 43$ induces the expression of OA-associated proteins such as MMP-1, MMP-13, and ADAMTS, a disintegrin-like and metalloproteinase with a thrombospondin type 1 motif (Fig. 1) [81].

Moreover, a collagen-induced arthritis rat model of RA [79] showed increased synovial Cx43 expression compared to control rats. In vitro lipopolysaccharide inflammatory stimulus also enhanced $\mathrm{Cx} 43$ expression, and the MMP increase in response to IL- 1 was shown to be $\mathrm{Cx} 43$ dependent in cultured synovial fibroblasts [82, 83]. More importantly, in a genetic silencing study of Cx43, rats treated with short interfering RNA directed against the Cx43 gene (siCx43) showed reductions in joint swelling, arthritis scores, and numbers of osteoclast-like cells. In culture, siCx 43 reversed the lipopolysaccharide (LPS)-induced upregulation of TNF- $\alpha$, IL- 6 , and IL- $1 \beta$ mRNAs [83].

Human patients with oculodentodigital dysplasia (ODDD) have mutations in $\mathrm{Cx} 43$ and show craniofacial abnormalities, aplastic or hypoplastic middle phalanges, syndactyly, and broad tubular long bones, indicating that connexins have a role in skeletal development [33]. Esseltine et al. obtained induced pluripotent stem cells (iPSCs) from a patient with a connexin-linked ODDD and found that, compared to wild-type iPSCs, they showed reduced Cx43 mRNA and protein and impaired channel function, which translated to delayed osteoblast differentiation, along with delayed expression of collagen-I bone sialoprotein (BSP) and osteopontin (OPN) in differentiated ODDD cells [84]. However, some mutations found in patients with ODDD can lead to reductions in gap junctions but also a hemichannel gain of function [85].

To discriminate between the roles of hemichannels and gap junctions in ODDD, two mouse models expressing dominant negative mutants of $\mathrm{Cx} 43$ have been developed. The first, R67W, has the ability to form functional hemichannels, but not gap junction channels, whereas the second, $\Delta 130-136$, has complete loss of $\mathrm{Cx} 43$ function [86]. The researchers found that while $\Delta 130-136$ mice showed reduced bone mass and aberrant bone structure, R67W mice had only a few abnormalities. However, they did not evaluate the gain or loss of hemichannel functionality.

Other mouse models have also been developed to help elucidate the function of $\mathrm{Cx} 43$ in bone. Mice with total Cx43 knockout (KO) die as a consequence of a cardiac phenotype, but during embryonic development, their bones show reduced mineralization, cortical thinning, and increased porosity [87, 88]. Meanwhile, studies using conditional KO models have pointed to differential roles of $\mathrm{Cx} 43$ at different stages of osteoblastic maturation. It has been suggested that $\mathrm{Cx} 43$ might inhibit the proliferation of early osteoblast precursor cells, as conditional $\mathrm{Cx} 43 \mathrm{KO}$ mice show increases in this populations. However, when Cx43 is knocked out in lineage-committed cells, osteoblasts do not seem to be essential and cells differentiate normally $[89,90]$. Cx43-deficient mice also show impaired osteoblast differentiation and fracture repair (Fig. 1) [91].

Age-associated reduction of $\mathrm{Cx} 43$ in osteoblasts has been linked to bone loss and osteoporosis, and it could diminish parathyroid hormone (PTH)-dependent bone formation. Moreover, $\mathrm{Cx} 43$ seems to be essential for the anabolic proprieties of PTH when used to treat osteoporosis, as it prevents PTH-induced production of cAMP by osteoblastic cells [92-94].

Diminished Cx43 levels in osteoblast and osteocytes could also influence the activity of bisphosphonates, the most commonly prescribe anti-osteoporotic drugs, by reducing their anti-apoptotic effects on these cells [95]. Bisphosphonates are reported to trigger the activation of the kinases Src and ERKs, which promotes cell survival by opening Cx43 hemichannels in a gap-junction-independent manner [96]. Moreover, bisphosphonate treatments that cause increased bone mineral density induce the formation of $\mathrm{Cx} 43$ hemichannels in osteocytes, which can result in increased ATP release.

Cx43 is considered essential for osteocyte viability and bone health, based on evidence from $\Delta 130-136$ and R67W mice, which also suggested that this effect is mediated by hemichannels rather than gap junctions [86]. $\mathrm{Cx} 43$ is also considered central to mechanosensing capability of osteocytes. Osteocytic MLO-Y4 cells express functional hemichannels that are activated by oscillating fluid flow through a mechanism that involves protein kinase $\mathrm{C}$ and promotes ATP release [97].

Conversely, although in vitro studies showed that $\mathrm{Cx} 43$ deficient cells have reduced responsiveness to biomechanical signals, Cx43-deficient mice display an enhanced anabolic response to mechanical load in vivo [98, 99]. This could be explained by a mechanism in which $\mathrm{Cx} 43$ deficiency leads to enhanced bone formation and resorption as well as enhanced response to load and decreased response [100].

In line with this, Zhang et al. reported that mice with osteocyte-specific $\mathrm{Cx} 43$ deficiency showed increased bone resorption and osteoclastogenesis due to osteocyte-mediated changes in RANKL/OPG ratio [99]. Further, Cx43 is believed to influence osteoclastogenesis, allowing cell fusion, as blocking gap-junctional communication inhibits 
bone resorption in vitro [101]. However, no direct function of hemichannels in osteoclastogenesis has been described, and in vivo studies will be required to demonstrate whether they play a role.

\section{Panx1 in the joint}

All three pannexins have been detected in murine chondrocytes, with Panx1 most abundantly expressed (Fig. 2). Studies using polydimethylsiloxane of varied stiffness as a cell culture substrate indicate that cell-cell communication in chondrocytes is mediated by Panx 1 in response to stiffness and that this is critical for chondrocyte metabolism and cartilage tissue engineering $[63,102]$.

Joint pain during arthritis is produced by aberrant nociceptive circuits activated in the central nervous system [103], and ATP is released during tissue injury and critically modulates microglial activity [104]. Mousseau et al. found that joint injury is followed by an increase in nociceptive output that depends on Panx1 expressed on microglia. They observed that pharmacological and genetic inhibition of Panx 1 ameliorated mechanical joint pain in rodents. Moreover, continuous systemic treatment with probenecid (a US FDA-approved broad-spectrum Panx1 inhibitor) prevented the reduction in mechanical threshold that occurs in rats with monosodium iodoacetate (MIA)-induced joint injury (which mimics arthritis) and blocked the increase in IL- $1 \beta$ that plays a dominant role in promoting joint pain [105].

The functional role of Panx 1 channels is cell type specific. Extracellular ATP is sensed by P2X7 and P2X4 receptors and mediates activation of the NLRP3 inflammasome during inflammation [106-108]. The NLRP3 inflammasome is a multiprotein complex that takes part in the innate immunity machinery [109] and whose activation leads to

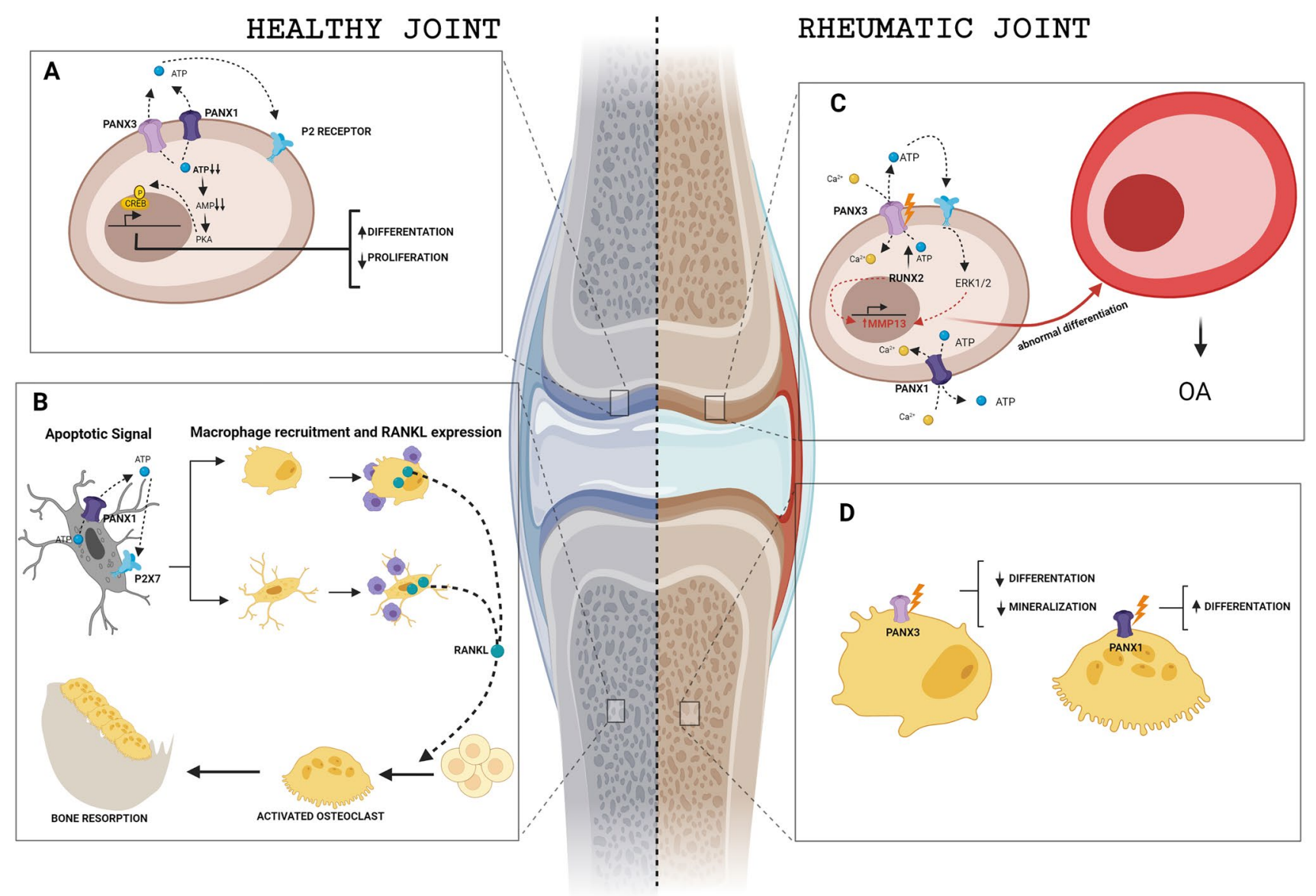

Fig. 2 Role of pannexin channels in healthy and arthritic joints. A) In healthy cartilage, chondrocytes mediate ATP release by Panx3. This leads a decrease in intracellular ATP, activation of phosphokinase A, and phosphorylation of CREB, a transcription factor that induces cell proliferation inhibition. B) In bone, the release of ATP by Panx1 is a signal of osteocyte apoptosis, causing macrophage recruitment and RANKL release that enables osteoclast activation and increased bone resorption. C) In rheumatic disease, the release of ATP mediated by Panx 3 via Runx 2 in chondrocytes activates $\mathrm{P} 2$ receptors. This leads to a repetitive cascade of signaling mediated by ERK1/2 and MMP13, which direct an aberrant differentiation to hypertrophic chondrocyte phenotype. D) Rheumatic bone disease alters Panx3 activity in osteoblasts and Panx 1 activity in osteoclasts 
activation of intracellular caspase 1 and secretion of proinflammatory IL- $1 \beta$ and IL-18. Panx 1 directly interacts with the $\mathrm{P} 2 \mathrm{X} 7$ receptor, and this interaction has been associated with NLRP3 activation [110, 111]. The P2X7/Panx1 complex directly binds to caspase- 1 and induces IL- $1 \beta$ release and pyroptosis in neurons and astrocytes [108]. Pharmacological and genetic inhibition of the $\mathrm{P} 2 \mathrm{X} 7$ receptor ameliorates mechanical joint pain in rodents in a similar manner to the blockade of Panx1 [105].

Moreover, the caspase-mediated activation of these pathways by the Panx1/P2X7 receptor complex and ATP release serves as a 'find me' signal necessary for macrophage recruitment during apoptosis [42]. Panx 1 activation and ATP release in apoptotic osteocytes, activated by the $\mathrm{P} 2 \mathrm{X} 7$ receptor, enhances RANKL expression in neighboring osteocytes and osteoblasts, induces macrophage recruitment, and increases osteoclast abundance in adjacent bone surface [112]. This cell fusion during osteoclast maturation is due to P2X7/Panx1-mediated ATP release that also enhances bone resorption [113-115]. The attenuation of Panx1 bone resorption that occurs in Panx1 KO mice after osteocyte apoptosis indicates that Panx1-mediated ATP release is a prerequisite for bone resorption [116].

Osteocyte apoptosis triggers bone remodeling by inducing neighboring viable osteocytes to produce RANKL [117] (Fig. 2). This process begins early in apoptosis, suggesting that signals involved in apoptosis play a key role in inducing viable osteocytes to produce osteoclastogenic cytokines. ATP and UTP together with lysophosphatidylchloline (lysoPC) and the chemokine CX3CL1 have been identified as 'find me' signals in the early phase of apoptosis [118]. Osteocytes co-express Panx1 and the P2X7 receptor and activate caspase-dependent Panx1 activation and channel opening during apoptosis $[97,119]$. Work in Panx 1 KO animals has demonstrated that Panx 1 does not participate in osteocyte apoptosis mediated by bone fatigue and microdamage, but is essential for RANKL expression triggered by apoptotic osteocytes and the initiation of osteoclastic bone remodeling. Similarly, work in $\mathrm{P} 2 \mathrm{X} 7$ receptor knockdown mice indicated that both the $\mathrm{P} 2 \mathrm{X} 7$ receptor and Panx 1 are essential during osteocyte apoptosis and RANKL release associated with fatigue and microdamage [116]. Although the exact mechanism involved is not clear, it is likely to be a paracrine mechanism whereby ATP is released via caspase3-mediated Panx1 opening in apoptotic osteocytes and activating the $\mathrm{P} 2 \mathrm{X} 7$ receptor in viable osteocytes [116]. Because Panx 1 and $\mathrm{P} 2 \mathrm{X} 7$ receptor $\mathrm{KO}$ are total in the mouse system used, and both genes are ubiquitously expressed, alterations in other cells may contribute to RANKL expression and bone remodeling in microdamage [56]. This finding is consistent with results indicating that both Panx 1 and the P2X7 receptor are essential for osteoclast differentiation and macrophage fusion in vitro [114].
During bone digestion, membrane components of the ruffled border also need to be recycled after macropinocytosis of digested bone materials $[120,121]$. Macropinocytosis is a non-selective endocytic pathway that consists in the uptake of nutrients and proteins from the extracellular space by invagination of the plasma membrane, which can produce changes in cell size [122]. It has been shown, that, elevated ATP levels in the extracellular space can regulate the macropinocytosis process in murine neuroblastoma cell line Neuro2a via internalization of Panx 1 channel. This suggests that ATP via Panx1 and P2X7 may not only act as a chemoattractant signal in macrophages [25] and in osteoclasts [114], but as a signal to internalize Panx1 by macropinocytosis. This relationship between Panx 1 and macropinocytosis occurs in the carcinogenic processes, in which ATP acts as a growth factor or energy source if internalized [123].

Furthermore, Panx 1 acts as a mechanosensitive channel and as a key mediator in intercellular signaling and in inflammatory responses [110, 124]. The global Panx 1 knockout mouse model has demonstrated that Panx 1 is essential for load-induced skeletal responses. Both Panx 1 and $\mathrm{P} 2 \mathrm{X} 7$ receptor expression are regulated in vivo by mechanical loading in osteocyte-enriched wild-type bones in a loading time-dependent manner [125]. These findings demonstrate a functional interaction of the $\mathrm{P} 2 \mathrm{X} 7$ receptor/ Panx1 signaling complex that is crucial for osteocyte mechanosignaling. Loss of Panx1 does not affect mineral apposition rate, which represents the activity of osteoblasts, but it modulates the rate at which bone is formed, consistent with an alteration in load-induced bone remodeling [125]. Although the absence of Panx 1 downregulates $\beta$-catenin expression in melanoma cells [126], $\beta$-catenin expression in non-loaded Panx1 knockout $\left(\right.$ Panx $\left.^{-/-}\right)$osteocyteenriched cells is unaffected. However, mechanical loading in Panx $^{-/-}$bones significantly downregulates $\beta$-catenin and upregulates sclerostin, indicative of crosstalk between Panx 1 and $W n t / \beta$-catenin signaling [114]. Similarly, SerefFerlengez et al. have demonstrated that the complex formed by Panx 1 and the $\mathrm{P} 2 \mathrm{X} 7$ receptor and altered ATP signaling impair osteocytes and osteoblast mechanosignaling under high-glucose conditions [127].

\section{Panx2 in the joint}

Panx 2 is more ubiquitously expressed than was suggested by the initial reports that it was exclusive to the central nervous system, including cerebellum, cerebral cortex, medulla, occipital pole frontal lobe, temporal lobe, and putamen; northern blot analysis has revealed Panx 2 expression in rodent eyes as well as thyroid, kidney, liver, and rat cochlear system [54, 128-130]. Using two novel monoclonal antibodies to Panx2 (N121A/1 and N121A/31), Panx2 expression has been found in murine heart, lung, stomach, spleen, spinal 
cord, skin, eye, colon, and testis [131]. Unfortunately, there is little data about Panx2 expression in bone or cartilage. Using predesigned TaqMan assays, Yorgan et al. studied the expression of pannexins in different tissues including spine, femur, and calvaria and found Panx 2 expression by qRT-PCR in murine calvaria, but they did not observe any changes in expression during osteoblast differentiation [132].

\section{Panx3 in the joint}

As described above, Panx 3 is expressed in pre- and hypertrophic chondrocytes as well as mature osteoblasts and has been suggested to play a role in their differentiation (Fig. 2) $[55,133]$. In the chondrogenic cell line ATDC5, Panx3 promotes chondrocyte differentiation by regulating intracellular ATP/cAMP levels [55]. Iwamoto et al. showed that ATP release into the extracellular space by Panx3 is responsible for PTH-mediated cell proliferation inhibition, as well as decreasing intracellular levels of cAMP and CREB phosphorylation [55]. During development, Panx3 expression at sites of intramembranous and endochondral ossification begins as early as E13-E13.5 [133]. In the growth plate, Panx3 expression precedes chondrocyte mineralization and co-localizes with bone development markers such as Col10 $\alpha 1$ and OPN [133]. Moreover, Panx3 promoter is transactivated with runtrelated transcription factor 2 (Runx2), a key transcription factor for normal bone formation that also promotes MMP13 expression [134].

In vivo, genetic deletion of Panx3 in mice leads to abnormal differentiation of hypertrophic chondrocytes; Lac of Panx3 plays a role in joint diseases and a delay in osteoblast differentiation and mineralization [134]. Moon et al. reported elevated Panx 3 abundance in damaged areas of cartilage in osteoarthritic mice and humans [9]. Global or Cre/loxP cartilage-selective Panx 3 knockdown mice were resistant to an OA induction procedure known as destabilization of medial meniscus surgery to induce OA (DMM-OA). Furthermore, Panx3 and Panx 1 levels were increased in osteophytes in DMM-operated control mice but not Panx3deficient mice [135]. This high Panx 1 and Panx3 expression results from osteophyte growth and development, that is similar to endochondral ossification and therefore leads to a similar pattern of protein expression. The altered mechanical environment that follows joint injury causes Runx2-mediated Panx3 induction, promoting ATP release from articular chondrocytes. The increase in extracellular ATP activates P2 receptors and downstream effectors such as ERK1/2. This cascade activates a vicious cycle with Runx2, Panx3, and MMP13 activation that leads to a complete destruction of the articular cartilage and joint [136-138]. It has further been reported that loss of Panx 3 has no other consequence for joint development and health. This suggest that Panx 1 might be sufficient to mediate normal joint development and in permanent adult cartilage [135].

In $\mathrm{C} 2 \mathrm{C} 12$ cells, an osteoprogenitor cell line derived from mouse myoblasts, and in primary calvarial cells, Panx3 is located in plasma membrane and regulates osteoblast differentiation (Fig. 2) as its expression is induced during the transition from cell proliferation to differentiation [139]. During osteoblast differentiation, Panx3 functions as a hemichannel that releases intracellular ATP into the extracellular space. This released ATP binds to purinergic receptors in an autocrine or paracrine manner, activates the PI3K-Akt signaling pathway, and mediates the activation of endoplasmic reticulum $\mathrm{Ca}^{2+}$ channels due to Panx3 opening [55]. This $\mathrm{Ca}^{2+}$-binding activates calmodulin $(\mathrm{CaM}) /(\mathrm{CN})$ signaling pathways that, upon activation of nuclear factor of activated T-cells calcineurin-dependent 1 (NFATc1), promotes the expression of Osterix and, in turn, induces the expression of osteoblast genes such as those encoding alkaline phosphatase (ALP) and osteocalcin (Ocn) [140-142]. Moreover, Panx3 activation can promote the degradation of p53, an inhibitor of osteoblast differentiation, by activating the Akt/mouse double-minute 2 homolog (MDM2) pathway. In a paracrine manner, the Panx3 gap junction propagates intracellular $\mathrm{Ca}^{2+}$ to neighboring cells to promote osteoblast differentiation [140, 142]. Both primary cultured osteoblasts and the MC3T3-E1 pre-osteoblast cell line express increasing levels of Panx 3 as they differentiate [133]. These increases mirror those of osteogenic markers such as Alpl, Ibsp, and Sp7 during differentiation. Moreover, Panx3 expression in osteoblasts increases MDM2 phosphorylation, promotes $\mathrm{p} 53$ degradation, and stimulates Smad1/5 phosphorylation [55].

One mechanism specific to the function of Panx 3 endoplasmic reticulum $\mathrm{Ca}^{2+}$ channels is the phosphorylation of serine 68 (Ser68) of Panx3 to promote osteoblast differentiation [143]. Mutation of this residue to alanine was sufficient to inhibit Panx3-mediated osteoblast differentiation as it induces depletion of Osterix and ALP expression. Panx3 Ser68 phosphorylation has been found in pre-hypertrophic and hypertrophic chondrocytes, bone areas of the newborn growth plate, and the endoplasmic reticulum membranes in C2C12 cells [143]. These data indicate that this phosphorylation is an essential step controlling the gating of the Panx 3 endoplasmic reticulum $\mathrm{Ca}^{2+}$ channel to promote osteogenesis, and that it is necessary for osteoblast differentiation but not osteoprogenitor proliferation. Several mechanisms have been proposed whereby this Ser68 phosphorylation of Panx3 at the endoplasmic reticulum membrane might be modulated by a cytoplasmic kinase. It is possible that a protein complex formed by Akt and other molecules, and a signaling pathway they control, may be necessary to activate Panx3 as a $\mathrm{Ca}^{2+}$ channel [143]. 5' AMP-activated protein kinase (AMPK) can form a complex with Akt to activate 
Panx3 endoplasmic reticulum $\mathrm{Ca}^{2+}$ channel. AMPK activity regulates Panx 3 proliferation and the differentiation of odontoblasts through ATP-releasing hemichannel activities [144]. BMP2 is another candidate for forming a complex with Akt, because it regulates Panx3 expression and the activation of the Panx 3 signaling pathway [140, 141]. Both Smad-dependent signaling and an independent pathway, such as MAPK signaling, may interact to produce Panx3 endoplasmic reticulum $\mathrm{Ca}^{2+}$ channel activation. Another residue important for Panx 3 activity (though less so than Ser68) is Ser303, whose mutation to alanine inhibits Panx3mediated ALP activity [143]. All together, these results suggest that Panx 3 phosphorylation occurs at an early stage and declines during development. This may be because in the transition from proliferation to differentiation, cells normally require substantial energy flow, with enormous exchanges of energy, and this might be regulated by phosphorylation of Panx 3 in the endoplasmic reticulum to control intracellular $\mathrm{Ca}^{2+}$ levels.

Panx 3 knockdown in zebrafish causes delayed osteoblast differentiation and mineralization and cartilage deformity [134]. Similarly, osteoblast differentiation is induced by Panx3-mediated ATP release and downstream PI3K/AKT signaling, and KO zebrafish demonstrated delayed osteoblast differentiation and mineralization [7, 10]. Investigations of animals lacking Panx3 either in the osteoblast lineage or ubiquitously indicate that Panx 3 expression in osteoblasts is not required for postnatal bone remodeling. As described previously for cartilage, it is possible that the loss of Panx3 in both Panx 3 conditional knockout (Panx $3^{\text {flff }}$; Run $x 2$-Cre) and $P a n x 3^{-1-}$ mice vs. their phenotypically normal littermates can be compensated by the action of Panx1 [132].

\section{Conclusions and future directions}

In this review, we have discussed the presence of connexins and pannexins in joint tissue and their relevance to the initiation of rheumatic diseases such as OA and RA. Chondrocytes, osteoblasts, and osteoclasts, the main cell types found in joints, all express one or more isoforms of both connexins and pannexins. Moreover, the regulation of ATP channels, including connexins and pannexins, is altered as a consequence of joint diseases.

Among the connexins, $\mathrm{Cx} 43$ levels in cartilage and synovial membrane are elevated during the onset of disease and inflammation [63, 78-80]. Bone is also affected, as Cx43 prevents early osteoblast differentiation $[89,90]$. There is disagreement about whether the age-associated reduction of Cx43 in osteoblasts might contribute to bone loss and osteoporosis [92]. However, studies to date seem to indicate that inhibiting the reduction of $\mathrm{Cx} 43$ in joint tissues might be beneficial in preventing the progression of joint diseases, taking into account the inflammatory component of the disease pathologies as well as the relevant role of MMPs in these pathologies [64, 81].

Among the pannexins, Panx 1 mediates the response to stiffness in cartilage but also joint pain [63, 102, 103]. As pain is the main factor in joint disease causing disability, its attenuation is a very attractive target when developing treatments, especially considering that previous strategies targeting pain mediators have been unsuccessful [145].

In addition, Panx1/P2X7 receptor complex function and ATP release together act as a 'find me' signal necessary for macrophage recruitment [42], osteocyte apoptosis, and enhanced bone resorption [113, 117]. This could have implications for treating bone pathologies such as osteoporosis, and preliminary studies have begun to harness its potential as a means to prevent bone loss [146].

Panx3 is involved in the cartilage damage seen in $\mathrm{OA}$ in both mice and humans [9] and also promotes hypertrophic chondrocyte differentiation $[55,133]$. This is significant especially when considering that chondrocytes from OA patients show a hypertrophic-like phenotype, and preventing the development of this phenotype has been proposed to slow or prevent OA progression [147].

To further clarify this, however, we will need to better understand whether hemichannels exist in cells of the osteoblastic lineage and whether their controversial roles described herein represent real effects. Also, further investigation will be needed to elucidate the different roles of gap junctions as compared to hemichannels in joint tissues and how their interplay might affect joint disease.

In conclusion, although we focus here on OA and RA, improved understanding the modulation of connexins and pannexins in joint tissues could provide attractive treatment approaches that could also benefit the treatment of all joint diseases s, which are increasingly needed given that the aging of the population, along with the rising prevalence of metabolic dysfunction, are increasing the socioeconomic burden of joint diseases with every year that passes.

Author contribution $\mathrm{AL}-\mathrm{V}$ and $\mathrm{AM}$ were responsible for organizing the manuscript. AL-V, MM-B, and AM performed literature search, data analysis, and wrote the manuscript. $\mathrm{BC}$ had the idea for the review and critically edit and revised the manuscript. R.L. and G.H.-B. revised and edited the manuscript.

Funding A.M. was supported by "Instituto de Salud Carlos III" through the "Miguel Servet" Program (CP15/00053), co-funded by the "Fondo Europeo de Desarrollo Regional (FEDER)." No other competing interests exist. This work was supported by grants from the New York University (NYU) School of Medicine Applied Research Support Fund and the US National Institutes of Health (R01 AR068593), by the NYU-HHC Clinical and Translational Science Institute (UL1 
TR000038) and the NYU DART Pathology Core, and by a research grant from the Spanish Instituto de Salud Carlos III (PI16/00991, PI19/00744).

Data availability Data sharing not applicable—no new data generated.

\section{Declarations}

Conflict of interest A.M. has filed a patent on the use of adenosine A2AR agonists to prevent prosthesis loosening (pending) and a separate patent on the use of A2AR agonists and agents that increase adenosine levels to promote bone formation/regeneration. R.L. and G.H.-B. have filed a patent on the use of 6-shogaol in osteoarthritis. A.L.-V. and M.M.-B. have no conflicts of interest. B.C. has consulted for Eli Lilly \& Co., Horizon Pharmaceuticals, and AstraZeneca. B.C. is a founder and Director of the Scientific Advisory Board of Regenosine, Inc. and has equity in Regenosine, Inc.

Ethical approval Not applicable.

Informed consent Not applicable.

Open Access This article is licensed under a Creative Commons Attribution 4.0 International License, which permits use, sharing, adaptation, distribution and reproduction in any medium or format, as long as you give appropriate credit to the original author(s) and the source, provide a link to the Creative Commons licence, and indicate if changes were made. The images or other third party material in this article are included in the article's Creative Commons licence, unless indicated otherwise in a credit line to the material. If material is not included in the article's Creative Commons licence and your intended use is not permitted by statutory regulation or exceeds the permitted use, you will need to obtain permission directly from the copyright holder. To view a copy of this licence, visit http://creativecommons.org/licenses/by/4.0/.

\section{References}

1. Lampa J (2019) Pain without inflammation in rheumatic diseases. Best Pract. Res. Clin. Rheumatol 33:101439

2. Barbour KE, Helmick CG, Boring M, Brady TJ (2017) Vital signs: prevalence of doctor-diagnosed arthritis and arthritisattributable activity limitation-United States, 2013-2015. MMWR Morb Mortal Wkly Rep 66:246-253

3. Theis KA, Steinweg A, Helmick CG, Courtney-Long E, Bolen JA, Lee R (2019) Which one? What kind? How many? Types, causes, and prevalence of disability among U.S. adults. Disabil. Health J 12:411-421

4. Alves F, Gonçalo M (2019) Suspected inflammatory rheumatic diseases in patients presenting with skin rashes. Best Pract. Res. Clin. Rheumatol 33:101440

5. Macfarlane E, Seibel MJ, Zhou H (2020) Arthritis and the role of endogenous glucocorticoids. Bone Res 8:1-17

6. Hootman JM, Helmick CG, Barbour KE, Theis KA, Boring MA (2016) Updated projected prevalence of self-reported doctor-diagnosed arthritis and arthritis-attributable activity limitation among US adults, 2015-2040. Arthritis Rheumatol 68:1582-1587

7. United States Bone and Joint Initiative: The Burden of Musculoskeletal Diseases in the United States (BMUS), 2020-04-10 Fourth Edition, forthcoming. Rosemont, I. A. at http://www. boneandjointburden.org. A. on (date). BMUS: The Burden of
Musculoskeletal Diseases in the United States I Prevalence, Societal and Economic Cost.

8. Rasch EK, Hirsch R, Paulose-Ram R, Hochberg MC (2003) Prevalence of rheumatoid arthritis in persons 60 years of age and older in the United States: effect of different methods of case classification. Arthritis Rheum 48:917-926

9. Katz JN, Arant KR, Loeser RF (2021) Diagnosis and treatment of hip and knee osteoarthritis: a review. JAMA J Am Med Assoc 325:568-578

10. Berenbaum F (2013) Osteoarthritis as an inflammatory disease (osteoarthritis is not osteoarthrosis!). Osteoarthr Cartil 21:16-21

11. Elsaman AM, Sayed A, Radwan AR (2020) Hand dominance in early and established rheumatoid arthritis: evaluation by dynamometer, ritchie index and musculoskeletal ultrasound: a cross sectional study. Reumatismo 72:131-144

12. Tilvawala R, Nguyen SH, Maurais AJ, Nemmara VV, Nagar M, Salinger AJ, Nagpal S, Weerapana E, Thompson PR (2018) The rheumatoid arthritis-associated citrullinome. Cell Chem Biol 25:691-704.e6

13. Gierut A, Perlman H, Pope RM (2010) Innate immunity and rheumatoid arthritis. Rheum Dis Clin North Am 36:271-296

14. Bhattaram P, Chandrasekharan U (2017) The joint synovium: a critical determinant of articular cartilage fate in inflammatory joint diseases. Semin Cell Dev Biol 62:86-93

15. Sophia Fox AJ, Bedi A, Rodeo SA (2009) The basic science of articular cartilage: structure, composition, and function. Sports Health 1:461-468

16. Wong M, Carter DR (2003) Articular cartilage functional histomorphology and mechanobiology: a research perspective. Bone 33:1-13

17. Sanchez C, Deberg MA, Piccardi N, Msika P, Reginster JYL, Henrotin YE (2005) Subchondral bone osteoblasts induce phenotypic changes in human osteoarthritic chondrocytes. Osteoarthr Cartil 13:988-997

18. Chen X, Wang Z, Duan N, Zhu G, Schwarz EM, Xie C (2018) Osteoblast-osteoclast interactions. Connect Tissue Res 59:99-107

19. Crockett JC, Rogers MJ, Coxon FP, Hocking LJ, Helfrich MH (2011) Bone remodelling at a glance. J Cell Sci 124:991-998

20. Antonioli L, Blandizzi C, Pacher P, Haskó G (2019) The purinergic system as a pharmacological target for the treatment of immune-mediated inflammatory diseases. Pharmacol Rev 71:345-382

21. Di Virgilio F, Vuerich M (2015) Purinergic signaling in the immune system. Auton Neurosci Basic Clin 191:117-123

22. Idzko M, Ferrari D, Eltzschig HK (2014) Nucleotide signalling during inflammation. Nature 509:310-317

23. Junger WG (2011) Immune cell regulation by autocrine purinergic signalling. Nat Rev Immunol 11:201-212

24. Dou Y, Wu HJ, Li HQ, Qin S, Wang YE, Li J, Lou HF, Chen Z, Li XM, Luo QM, Duan S (2012) Microglial migration mediated by ATP-induced ATP release from lysosomes. Cell Res 22:1022-1033

25. Kronlage, M., Song, J., Sorokin, L., Isfort, K., Schwerdtle, T., Leipziger, J., Robaye, B., Conley, P. B., Kim, H. C., Sargin, S., Schön, P., Schwab, A., and Hanley, P. J. (2010) Autocrine purinergic receptor signaling is essential for macrophage chemotaxis. Sci. Signal.3

26. Del Rey A, Renigunta V, Dalpke AH, Leipziger J, Matos JE, Robaye B, Zuzarte M, Kavelaars A, Hanley PJ (2006) Knockout mice reveal the contributions of $\mathrm{P} 2 \mathrm{Y}$ and $\mathrm{P} 2 \mathrm{X}$ receptors to nucleotide-induced $\mathrm{Ca} 2+$ signaling in macrophages. J Biol Chem 281:35147-35155

27. Saéz, P. J., Vargas, P., Shoji, K. F., Harcha, P. A., LennonDuméni, A. M., and Saéz, J. C. (2017) ATP promotes the fast 
migration of dendritic cells through the activity of pannexin 1 channels and P2X7 receptors. Sci. Signal.10

28. Gachet C (2008) P2 receptors, platelet function and pharmacological implications. Thromb Haemost 99:466-472

29. Kahner BN, Shankar H, Murugappan S, Prasad GL, Kunapuli SP (2006) Nucleotide receptor signaling in platelets. J Thromb Haemost 4:2317-2326

30. Lazarowski ER (2012) Vesicular and conductive mechanisms of nucleotide release. Purinergic Signal 8:359-373

31. Lohman AW, Isakson BE (2014) Differentiating connexin hemichannels and pannexin channels in cellular ATP release. FEBS Lett 588:1379-1388

32. Beyer EC, Berthoud VM (2018) Gap junction gene and protein families: Connexins, innexins, and pannexins. Biochim Biophys Acta - Biomembr 1860:5-8

33. Donahue HJ, Qu RW, Genetos DC (2018) Joint diseases: from connexins to gap junctions. Nat Rev Rheumatol 14:42-51

34. Nielsen MS, Axelsen LN, Sorgen PL, Verma V, Delmar M, Holstein-Rathlou NH (2012) Gap junctions. Compr Physiol 2:1981-2035

35. Sáez JC, Leybaert L (2014) Hunting for connexin hemichannels. FEBS Lett 588:1205-1211

36. Laird DW (2006) Life cycle of connexins in health and disease. Biochem. J 394:527-543

37. Nualart-Marti A, Del Molino EM, Grandes X, Bahima L, MartinSatué M, Puchal R, Fasciani I, González-Nieto D, Ziganshin B, Llobet A, Barrio LC, Solsona C (2013) Role of connexin 32 hemichannels in the release of ATP from peripheral nerves. Glia 61:1976-1989

38. Kang J, Kang N, Lovatt D, Torres A, Zhao Z, Lin J, Nedergaard M (2008) Connexin 43 hemichannels are permeable to ATP. J Neurosci 28:4702-4711

39. Schock SC, LeBlanc D, Hakim AM, Thompson CS (2008) ATP release by way of connexin 36 hemichannels mediates ischemic tolerance in vitro. Biochem Biophys Res Commun 368:138-144

40. Koval M, Isakson BE, Gourdie RG (2014) Connexins, pannexins and innexins: protein cousins with overlapping functions. FEBS Lett 588:1185

41. Dosch, M., Gerber, J., Jebbawi, F., and Beldi, G. (2018) Mechanisms of ATP release by inflammatory cells. Int. J. Mol. Sci.19

42. Billaud M, Lohman AW, Straub AC, Looft-Wilson R, Johnstone SR, Araj CA, Best AK, Chekeni FB, Ravichandran KS, Penuela S, Laird DW, Isakson BE (2011) Pannexin1 regulates $\alpha 1$-adrenergic receptor- mediated vasoconstriction. Circ Res 109:80-85

43. Ransford GA, Fregien N, Qiu F, Dahl G, Conner GE, Salathe M (2009) Pannexin 1 contributes to ATP release in airway epithelia. Am J Respir Cell Mol Biol 41:525-534

44. Schenk, U., Westendorf, A. M., Radaelli, E., Casati, A., Ferro, M., Fumagalli, M., Verderio, C., Buer, J., Scanziani, E., and Grassi, F. (2008) Purinergic control of T cell activation by ATP released through pannexin-1 hemichannels. Sci. Signal.1

45. Bao L, Locovei S, Dahl G (2004) Pannexin membrane channels are mechanosensitive conduits for ATP. FEBS Lett 572:65-68

46. Deng Z, He Z, Maksaev G, Bitter RM, Rau M, Fitzpatrick JAJ, Yuan P (2020) Cryo-EM structures of the ATP release channel pannexin 1. Nat Struct Mol Biol 27:373-381

47. Jin Q, Zhang B, Zheng X, Li N, Xu L, Xie Y, Song F, Bhat EA, Chen Y, Gao N, Guo J, Zhang X, Ye S (2020) Cryo-EM structures of human pannexin 1 channel. Cell Res 30:449-451

48. Michalski, K., Syrjanen, J. L., Henze, E., Kumpf, J., Furukawa, H., and Kawate, T. (2020) The Cryo-EM structure of a pannexin 1 reveals unique motifs for ion selection and inhibition. Elife $\mathbf{9}$

49. Ambrosi C, Gassmann O, Pranskevich JN, Boassa D, Smock A, Wang J, Dahl G, Steinem C, Sosinsky GE (2010) Pannexin1 and pannexin 2 channels show quaternary similarities to connexons and different oligomerization numbers from each other. J Biol Chem 285:24420-24431

50. Sosinsky GE, Boassa D, Dermietzel R, Duffy HS, Laird DW, MacVicar BA, Naus CC, Penuela S, Scemes E, Spray DC, Thompson RJ, Zhao HB, Dahl G (2011) Pannexin channels are not gap junction hemichannels. Channels 5:193

51. Shestopalov VI, Panchin Y (2008) Pannexins and gap junction protein diversity. Cell Mol Life Sci 65:376-394

52. Baranova A, Ivanov D, Petrash N, Pestova A, Skoblov M, Kelmanson I, Shagin D, Nazarenko S, Geraymovych E, Litvin O, Tiunova A, Born TL, Usman N, Staroverov D, Lukyanov S, Panchin Y (2004) The mammalian pannexin family is homologous to the invertebrate innexin gap junction proteins. Genomics 83:706-716

53. Penuela S, Bhalla R, Gong XQ, Cowan KN, Celetti SJ, Cowan BJ, Bai D, Shao Q, Laird DW (2007) Pannexin 1 and pannexin 3 are glycoproteins that exhibit many distinct characteristics from the connexin family of gap junction proteins. J Cell Sci 120:3772-3783

54. Wang XH, Streeter M, Liu YP, Zhao HB (2009) Identification and characterization of pannexin expression in the mammalian cochlea. J Comp Neurol 512:336-346

55. Iwamoto T, Nakamura T, Doyle A, Ishikawa M, De Vega S, Fukumoto S, Yamada Y (2010) Pannexin 3 regulates intracellular ATP/cAMP levels and promotes chondrocyte differentiation. J Biol Chem 285:18948-18958

56. Penuela S, Gehi R, Laird DW (2013) The biochemistry and function of pannexin channels. Biochim Biophys Acta - Biomembr 1828:15-22

57. Mayan MD, Carpintero-Fernandez P, Gago-Fuentes R, MartinezDe-Ilarduya O, Wang HZ, Valiunas V, Brink P, Blanco FJ (2013) Human articular chondrocytes express multiple gap junction proteins: differential expression of connexins in normal and osteoarthritic cartilage. Am J Pathol 182:1337-1346

58. Gupta, A., Niger, C., Buo, A. M., Eidelman, E. R., Chen, R. J., and Stains, J. P. (2014) Connexin43 enhances the expression of osteoarthritis-associated genes in synovial fibroblasts in culture. BMC Musculoskelet. Disord.15

59. Zappitelli T, Chen F, Moreno L, Zirngibl RA, Grynpas M, Henderson JE, Aubin JE (2013) The G60S connexin 43 mutation activates the osteoblast lineage and results in a resorption-stimulating bone matrix and abrogation of old-age-related bone loss. J Bone Miner Res 28:2400-2413

60. McLachlan E, Plante I, Shao Q, Tong D, Kidder GM, Bernier SM, Laird DW (2008) ODDD-linked Cx43 mutants reduce endogenous $\mathrm{Cx} 43$ expression and function in osteoblasts and inhibit late stage differentiation. J Bone Miner Res 23:928-938

61. Genetos DC, Zhou Z, Li Z, Donahue HJ (2012) Age-related changes in gap junctional intercellular communication in osteoblastic cells. J Orthop Res 30:1979-1984

62. Chung DJ, Castro CHM, Watkins M, Stains JP, Chung MY, Szejnfeld VL, Willecke K, Theis M, Civitelli R (2006) Low peak bone mass and attenuated anabolic response to parathyroid hormone in mice with an osteoblast-specific deletion of connexin 43. J Cell Sci 119:4187-4198

63. Vander Molen MA, Rubin CT, McLeod KJ, McCauley LK, Donahue HJ (1996) Gap junctional intercellular communication contributes to hormonal responsiveness in osteoblastic networks. J Biol Chem 271:12165-12171

64. Plotkin LI, Lezcano V, Thostenson J, Weinstein RS, Manolagas SC, Bellido T (2008) Connexin 43 is required for the antiapoptotic effect of bisphosphonates on osteocytes and osteoblasts in vivo. $\mathrm{J}$ Bone Miner Res 23:1712-1721

65. Xu H, Gu S, Riquelme MA, Burra S, Callaway D, Cheng H, Guda T, Schmitz J, Fajardo RJ, Werner SL, Zhao H, Shang P, Johnson ML, Bonewald LF, Jiang JX (2015) Connexin 43 channels 
are essential for normal bone structure and osteocyte viability. J Bone Miner Res 30:550-562

66. Genetos DC, Kephart CJ, Zhang Y, Yellowley CE, Donahue HJ (2007) Oscillating fluid flow activation of gap junction hemichannels induces ATP release from MLO-Y4 osteocytes. J Cell Physiol 212:207-214

67. Ilvesaro J, Väänänen K, Tuukkanen J (2000) Bone-resorbing osteoclasts contain gap-junctional connexin-43. J Bone Miner Res 15:919-926

68. Pelegrin P, Surprenant A (2006) Pannexin-1 mediates large pore formation and interleukin- $1 \beta$ release by the ATP-gated P2X7 receptor. EMBO J 25:5071-5082

69. Komori, T. (2016) Cell death in chondrocytes, osteoblasts, and osteocytes. Int. J. Mol. Sci.17

70. Cheung WY, Fritton JC, Morgan SA, Seref-Ferlengez Z, BastaPljakic J, Thi MM, Suadicani SO, Spray DC, Majeska RJ, Schaffler MB (2016) Pannexin-1 and P2X7-receptor are required for apoptotic osteocytes in fatigued bone to trigger RANKL production in neighboring bystander osteocytes. J Bone Miner Res 31:890-899

71. Lemaire I, Falzoni S, Zhang B, Pellegatti P, Di Virgilio F (2011) The P2X 7 receptor and pannexin-1 are both required for the promotion of multinucleated macrophages by the inflammatory cytokine GM-CSF. J Immunol 187:3878-3887

72. Yorgan TA, Peters S, Amling M, Schinke T (2019) Osteoblastspecific expression of Panx 3 is dispensable for postnatal bone remodeling. Bone 127:155-163

73. Papachristou DJ, Pirttiniemi P, Kantomaa T, Papavassiliou AG, Basdra EK (2005) JNK/ERK-AP-1/Runx2 induction "paves the way" to cartilage load-ignited chondroblastic differentiation. Histochem Cell Biol 124:215-223

74. Waldman SD, Usprech J, Flynn LE, Khan AA (2010) Harnessing the purinergic receptor pathway to develop functional engineered cartilage constructs. Osteoarthr Cartil 18:864-872

75. Leong WS, Russell RG, Caswell AM (1994) Stimulation of cartilage resorption by extracellular ATP acting at P2-purinoceptors. BBA - Gen Subj 1201:298-304

76. Oh SK, Shin JO, Baek JI, Lee J, Bae JW, Ankamerddy H, Kim MJ, Huh TL, Ryoo ZY, Kim UK, Bok J, Lee KY (2015) Pannexin 3 is required for normal progression of skeletal development in vertebrates. FASEB J 29:4473-4484

77. Qiu F, Dahl G (2009) A permeant regulating its permeation pore: inhibition of pannexin 1 channels by ATP. Am J Physiol - Cell Physiol 296:C250

78. Wang, J., Ma, M., Locovei, S., Keane, R. W., and Dahl, G. (2007) Modulation of membrane channel currents by gap junction protein mimetic peptides: size matters. Am. J. Physiol. - Cell Physiol.293

79. Lohman, A. W., Leskov, I. L., Butcher, J. T., Johnstone, S. R., Stokes, T. A., Begandt, D., Delalio, L. J., Best, A. K., Penuela, S., Leitinger, N., Ravichandran, K. S., Stokes, K. Y., and Isakson, B. E. (2015) Pannexin 1 channels regulate leukocyte emigration through the venous endothelium during acute inflammation. Nat. Commun. 6

80. Weilinger NL, Tang PL, Thompson RJ (2012) Anoxia-induced NMDA receptor activation opens Pannexin channels via Src family kinases. J Neurosci 32:12579-12588

81. Poornima V, Vallabhaneni S, Mukhopadhyay M, Bera AK (2015) Nitric oxide inhibits the pannexin 1 channel through a cGMP-PKG dependent pathway. Nitric Oxide Biol Chem 47:77-84

82. Knight MM, Mcglashan SR, Garcia M, Jensen CG, Poole CA (2009) Articular chondrocytes express connexin 43 hemichannels and $\mathrm{P} 2$ receptors-a putative mechanoreceptor complex involving the primary cilium? J Anat 214(2):275-283
83. Varela-Eirín, M., Varela-Vázquez, A., Guitián-Caamaño, A., Paíno, C. L., Mato, V., Largo, R., Aasen, T., Tabernero, A., Fonseca, E., Kandouz, M., Caeiro, J. R., Blanco, A., and Mayán, M. D. (2018) Targeting of chondrocyte plasticity via connexin 43 modulation attenuates cellular senescence and fosters a proregenerative environment in osteoarthritis. Cell Death Dis.9

84. Garcia, M. and Knight, M. M. (2009) Cyclic loading opens hemichannels to release ATP as part of a chondrocyte mechanotransduction pathway. J. Orthop. Res.28, n/a-n/a

85. Leybaert L, Braet K, Vandamme W, Cabooter L, Martin PEM, Evans WH (2003) Connexin channels, connexin mimetic peptides and ATP release. Cell Commun Adhes 10:251-257

86. Bao, L., Sachs, F., and Dahl, G. (2004) Connexins are mechanosensitive. Am. J. Physiol. - Cell Physiol.287

87. Gomes P, Srinivas SP, Van Driessche W, Vereecke J, Himpens B (2005) ATP release through connexin hemichannels in corneal endothelial cells. Investig Ophthalmol Vis Sci 46:1208-1218

88. Tansey EE, Kwaku KF, Hammer PE, Cowan DB, Federman M, Levitsky S, McCully JD (2006) Reduction and redistribution of gap and adherens junction proteins after ischemia and reperfusion. Ann Thorac Surg 82:1472-1479

89. Pingguan-Murphy B, El-Azzeh M, Bader DL, Knight MM (2006) Cyclic compression of chondrocytes modulates a purinergic calcium signalling pathway in a strain rate- and frequency-dependent manner. J Cell Physiol 209:389-397

90. Chowdhury TT, Knight MM (2006) Purinergic pathway suppresses the release of $\mathrm{NO}$ and stimulates proteoglycan synthesis in chondrocyte/agarose constructs subjected to dynamic compression. J Cell Physiol 209:845-853

91. Millward-Sadler, S. J., Wright, M. O., Flatman, P., and Salter, D. (2004) ATP in the mechanotransduction pathway of normal human chondrocytes. undefined

92. Millward-Sadler SJ, Wright MO, Lee HS, Caldwell H, Nuki G, Salter DM (2000) Altered electrophysiological responses to mechanical stimulation and abnormal signalling through $\alpha 5 \beta 1$ integrin in chondrocytes from osteoarthritic cartilage. Osteoarthr Cartil 8:272-278

93. Hellio, M.-P., Graverand, L., Sciore, P., Eggerer, J., Rattner, J. P., Vignon, E., Barclay, L., Hart, D. A., and Rattner, J. B. (2001) Formation and phenotype of cell clusters in osteoarthritic meniscus. ARTHRITIS Rheum. $\mathbf{4 4}$

94. Hellio Le Graverand MP, Ou Y, Schield-Yee T, Barclay L, Hart D, Natsume T, Rattner JB (2001) The cells of the rabbit meniscus: their arrangement, interrelationship, morphological variations and cytoarchitecture. J. Anat 198(525):535

95. Giepmans BNG (2006) Role of connexin43-interacting proteins at gap junctions. Adv Cardiol 42:41-56

96. Giepmans BNG, Verlaan I, Hengeveld T, Janssen H, Calafat J, Falk MM, Moolenaar WH (2001) Gap junction protein connexin-43 interacts directly with microtubules. Curr Biol 11:1364-1368

97. Gago-Fuentes R, Bechberger JF, Varela-Eirin M, Varela-Vazquez A, Acea B, Fonseca E, Naus CC, Mayan MD (2016) The C-terminal domain of connexin 43 modulates cartilage structure via chondrocyte phenotypic changes. Oncotarget 7:73055-73067

98. Skiöldebrand E, Thorfve A, Björklund U, Johansson P, Wickelgren R, Lindahl A, Hansson E (2018) Biochemical alterations in inflammatory reactive chondrocytes: evidence for intercellular network communication. Heliyon 4:e00525

99. Tonon R, D'Andrea P (2000) Interleukin- $1 \beta$ increases the functional expression of connexin 43 in articular chondrocytes: evidence for a $\mathrm{Ca}^{2+}$-dependent mechanism. J Bone Miner Res 15:1669-1677

100. Kolomytkin, O. V., Marino, A. A., Waddell, D. D., Mathis, J. M., Wolf, R. E., Sadasivan, K. K., Albright, J. A., Michael Mathis, J., Wolf, R. E., Sadasivan, K. K., and Albright, J. A. (2002) 
IL-1 $\beta$-induced production of metalloproteinases by synovial cells depends on gap junction conductance. 282, C1254-C1260

101. Tsuchida S, Arai Y, Kishida T, Takahashi KA, Honjo K, Terauchi R, Inoue H, Oda R, Mazda O, Kubo T (2013) Silencing the expression of connexin 43 decreases inflammation and joint destruction in experimental arthritis. J Orthop Res 31:525-530

102. Esseltine JL, Shao Q, Brooks C, Sampson J, Betts DH, Séguin CA, Laird DW (2017) Connexin43 mutant patient-derived induced pluripotent stem cells exhibit altered differentiation potential. J Bone Miner Res 32:1368-1385

103. Dobrowolski R, Sommershof A, Willecke K (2007) Some oculodentodigital dysplasia-associated $\mathrm{Cx} 43$ mutations cause increased hemichannel activity in addition to deficient gap junction channels. J Membr Biol 219:9-17

104. Stains JP, Civitelli R (2016) Connexins in the skeleton. Semin Cell Dev Biol 50:31-39

105. Lecanda F, Warlow PM, Sheikh S, Furlan F, Steinberg TH, Civitelli R (2000) Connexin43 deficiency causes delayed ossification, craniofacial abnormalities, and osteoblast dysfunction. $\mathrm{J}$ Cell Biol 151:931-943

106. Loiselle AE, Wei L, Faryad M, Paul EM, Lewis GS, Gao J, Lakhtakia A, Donahue HJ (2013) Specific biomimetic hydroxyapatite nanotopographies enhance osteoblastic differentiation and bone graft osteointegration. Tissue Eng - Part A19:1704-1712

107. Plotkin LI, Bellido T (2001) Bisphosphonate-induced, hemichannel-mediated, anti-apoptosis through the Src/ERK pathway: a gap junction-independent action of connexin43. Cell Commun Adhes 8:377-382

108. Klein JC, Keith A, Rice SJ, Shepherd C, Agarwal V, Loughlin J, Shendure J (2019) Functional testing of thousands of osteoarthritis-associated variants for regulatory activity. Nat Commun 10:1-9

109. Zhang Y, Paul EM, Sathyendra V, Davison A, Sharkey N, Bronson S, Srinivasan S, Gross TS, Donahue HJ (2011) Enhanced osteoclastic resorption and responsiveness to mechanical load in gap junction deficient bone. PLoS ONE 6:23516

110. Lloyd SA, Loiselle AE, Zhang Y, Donahue HJ (2014) Shifting paradigms on the role of connexin43 in the skeletal response to mechanical load. J Bone Miner Res 29:275-286

111. Cai L, Liu W, Cui Y, Liu Y, Du W, Zheng L, Pi C, Zhang D, Xie J, Zhou X (2020) Biomaterial stiffness guides cross-talk between chondrocytes: implications for a novel cellular response in cartilage tissue engineering. ACS Biomater Sci Eng 6:4476-4489

112. Gwilym SE, Keltner JR, Warnaby CE, Carr AJ, Chizh B, Chessell I, Tracey I (2009) Psychophysical and functional imaging evidence supporting the presence of central sensitization in a cohort of osteoarthritis patients. Arthritis Care Res 61:1226-1234

113. Masuda, T., Ozono, Y., Mikuriya, S., Kohro, Y., Tozaki-Saitoh, H., Iwatsuki, K., Uneyama, H., Ichikawa, R., Salter, M. W., Tsuda, M., and Inoue, K. (2016) Dorsal horn neurons release extracellular ATP in a VNUT-dependent manner that underlies neuropathic pain. Nat. Commun.7

114. Mousseau, M., Burma, N. E., Lee, K. Y., Leduc-Pessah, H., Kwok, C. H. T., Reid, A. R., O’Brien, M., Sagalajev, B., Stratton, J. A., Patrick, N., Stemkowski, P. L., Biernaskie, J., Zamponi, G. W., Salo, P., McDougall, J. J., Prescott, S. A., Matyas, J. R., and Trang, T. (2018) Microglial pannexin-1 channel activation is a spinal determinant of joint pain. Sci. Adv.4

115. Kopp R, Krautloher A, Ramírez-Fernández A, Nicke A (2019) P2X7 interactions and signaling-making head or tail of it. Front Mol Neurosci 12:183

116. Ribeiro DE, Roncalho AL, Glaser T, Ulrich H, Wegener G, Joca $\mathrm{S}$ (2019) P2X7 receptor signaling in stress and depression. Int J Mol Sci 20:2778
117. Silverman WR, de Rivero Vaccari JP, Locovei S, Qiu F, Carlsson SK, Scemes E, Keane RW, Dahl G (2009) The pannexin 1 channel activates the inflammasome in neurons and astrocytes. J Biol Chem 284:18143-18151

118. Place DE, Kanneganti TD (2018) Recent advances in inflammasome biology. Curr Opin Immunol 50:32-38

119. Parzych K, Zetterqvist AV, Wright WR, Kirkby NS, Mitchell JA, Paul-Clark MJ (2017) Differential role of pannexin-1/ATP/ $\mathrm{P} 2 \mathrm{X} 7$ axis in IL-1 $\beta$ release by human monocytes. FASEB J 31:2439-2445

120. Buckley KA, Hipskind RA, Gartland A, Bowler WB, Gallagher JA (2002) Adenosine triphosphate stimulates human osteoclast activity via upregulation of osteoblast-expressed receptor activator of nuclear factor- $\mathrm{\kappa B}$ ligand. Bone 31:582-590

121. Iglesias, R., Locovei, S., Roque, A., Alberto, A. P., Dahl, G., Spray, D. C., and Scemes, E. (2008) P2X7 receptor-pannexin1 complex: pharmacology and signaling. Am. J. Physiol. - Cell Physiol.295

122. Kennedy OD, Laudier DM, Majeska RJ, Sun HB, Schaffler MB (2014) Osteocyte apoptosis is required for production of osteoclastogenic signals following bone fatigue in vivo. Bone 64:132-137

123. Elliott MR, Chekeni FB, Trampont PC, Lazarowski ER, Kadl A, Walk SF, Park D, Woodson RI, Ostankovich M, Sharma P, Lysiak JJ, Harden TK, Leitinger N, Ravichandran KS (2009) Nucleotides released by apoptotic cells act as a find-me signal to promote phagocytic clearance. Nature 461:282-286

124. Sandilos JK, Chiu YH, Chekeni FB, Armstrong AJ, Walk SF, Ravichandran KS, Bayliss DA (2012) Pannexin 1, an ATP release channel, is activated by caspase cleavage of its poreassociated C-terminal autoinhibitory region. J Biol Chem 287:11303-11311

125. Zhao H (2012) Membrane trafficking in osteoblasts and osteoclasts: new avenues for understanding and treating skeletal diseases. Traffic 13:1307-1314

126. Steenblock C, Heckel T, Czupalla C, Santo AIE, Niehage C, Sztacho M, Hoflack B (2014) The Cdc42 guanine nucleotide exchange factor FGD6 coordinates cell polarity and endosomal membrane recycling in osteoclasts. J Biol Chem 289:18347-18359

127. Stow JL, Hung Y, Wall AA (2020) Macropinocytosis: insights from immunology and cancer. Curr Opin Cell Biol 65:131-140

128. Boyce, A. K., van der Slagt, E., Sanchez-Arias, J. C., Anne Swayne, L., and Boyce -andrewboyce, A. K. (2020) ATP triggers macropinocytosis that internalizes and is regulated by PANX1. bioRxiv 2020.11.19.389072

129. Suadicani SO, Iglesias R, Wang J, Dahl G, Spray DC, Scemes E (2012) ATP signaling is deficient in cultured pannexin1-null mouse astrocytes. Glia 60:1106-1116

130. Seref-Ferlengez Z, Urban-Maldonado M, Sun HB, Schaffler MB, Suadicani SO, Thi MM (2019) Role of pannexin 1 channels in load-induced skeletal response. Ann N Y Acad Sci 1442:79-90

131. Penuela S, Gyeniss L, Ablack A, Churko JM, Berger AC, Litchfield DW, Lewis JD, Laird DW (2012) Loss of pannexin 1 attenuates melanoma progression by reversion to a melanocytic phenotype. J Biol Chem 287:29184-29193

132. Seref-Ferlengez Z, Maung S, Schaffler MB, Spray DC, Suadicani SO, Thi MM (2016) P2X7R-Panx1 complex impairs bone mechanosignaling under high glucose levels associated with type-1 diabetes. PLoS One 11:e0155107

133. Bruzzone R, Hormuzdi SG, Barbe MT, Herb A, Monyer H (2003) Pannexins, a family of gap junction proteins expressed in brain. Proc Natl Acad Sci U S A 100:13644-13649 
134. Dvoriantchikova G, Ivanov D, Panchin Y, Shestopalov VI (2006) Expression of pannexin family of proteins in the retina. FEBS Lett 580:2178-2182

135. Dvoriantchikova G, Ivanov D, Pestova A, Shestopalov V (2006) Molecular charaterization of pannexins in the lens. Mol Vis 12:1417-1426

136. Le Vasseur M, Lelowski J, Bechberger JF, Sin W-CC, Naus CC, Vasseur ML, Lelowski J, Bechberger JF, Sin W-CC, Naus CC (2014) Pannexin 2 protein expression is not restricted to the CNS. Front Cell Neurosci 8:392

137. Bond SR, Lau A, Penuela S, Sampaio AV, Underhill TM, Laird DW, Naus CC (2011) Pannexin 3 is a novel target for Runx2, expressed by osteoblasts and mature growth plate chondrocytes. J Bone Miner Res 26:2911-2922

138. Moon PM, Penuela S, Barr K, Khan S, Pin CL, Welch I, Attur M, Abramson SB, Laird DW, Beier F (2015) Deletion of Panx3 prevents the development of surgically induced osteoarthritis. J Mol Med 93:845-856

139. Hung, C. T., Allen, F. D., Mansfield, K. D., and Shapiro, I. M. (1997) Extracellular ATP modulates [CA2+](i) in retinoic acid-treated embryonic chondrocytes. Am. J. Physiol. - Cell Physiol.272

140. Ishikawa M, Iwamoto T, Nakamura T, Doyle A, Fukumoto S, Yamada Y (2011) Pannexin 3 functions as an ER Ca 2+ channel, hemichannel, and gap junction to promote osteoblast differentiation. J Cell Biol 193:1257-1274

141. Ishikawa M, Iwamoto T, Fukumoto S, Yamada Y (2014) Pannexin 3 inhibits proliferation of osteoprogenitor cells by regulating Wnt and p21 signaling. J Biol Chem 289:2839-2851

142. Koga T, Matsui Y, Asagiri M, Kodama T, De Crombrugghe B, Nakashima K, Takayanagi H (2005) NFAT and Osterix cooperatively regulate bone formation. Nat Med 11:880-885

143. Ishikawa, M., Williams, G., Forcinito, P., Ishikawa, M., Petrie, R. J., Saito, K., Fukumoto, S., and Yamada, Y. (2019) Pannexin $3 \mathrm{ER} \mathrm{Ca} 2+$ channel gating is regulated by phosphorylation at the Serine 68 residue in osteoblast differentiation. Sci. Rep.9
144. Iwamoto T, Nakamura T, Ishikawa M, Yoshizaki K, Sugimoto A, Ida-Yonemochi H, Ohshima H, Saito M, Yamada Y, Fukumoto $S$ (2017) Pannexin 3 regulates proliferation and differentiation of odontoblasts via its hemichannel activities. PLoS One 12:e0177557

145. Hochberg MC (2015) Serious joint-related adverse events in randomized controlled trials of anti-nerve growth factor monoclonal antibodies. Osteoarthr Cartil 23:S18-S21

146. Conesa-Buendía FMFM, Llamas-Granda P, Larrañaga-Vera A, Wilder T, Largo R, Herrero-Beaumont G, Cronstein B, Mediero A (2019) Tenofovir causes bone loss via decreased bone formation and increased bone resorption, which can be counteracted by dipyridamole in mice. J. Bone Miner. Res 34:e3665

147. Van der Kraan PM, Van den Berg WB (2012) Chondrocyte hypertrophy and osteoarthritis: role in initiation and progression of cartilage degeneration? Osteoarthr Cartil 20:223-232

Publisher's Note Springer Nature remains neutral with regard to jurisdictional claims in published maps and institutional affiliations.

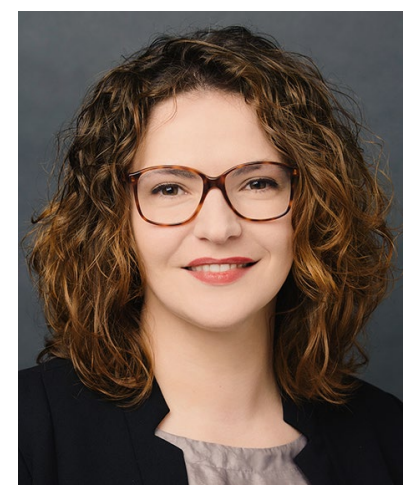

Ane Larranaga-Vera received the BS in Biotechnology in 2011 from Universitat de Lleida, Spain and the MS IN Molecular and cellular Biology in 2012 and the $\mathrm{PhD}$ in Molecular Biosciences in 2017 from Universidad Autonoma de Madrid, Spain. Currently she is working as a postdoctorla fellow in NYU School of Medicine, New York, NY. Her research interests include the study of adenosine receptors inmusculoskeletal pathology, incliding the molecular and cellular mechanisms of the diseases and the translational aspects by aiming to develop drugs that can be used in the clinic to improve the live quality of patients. 